\title{
Proposta para Formação Continuada de Docentes Online
} A Proposal for Continuing Education Course for Online Teachers

\author{
Natalia Xavier Pereira da Costa ${ }^{1}$ \\ Roberta Flavia Ribeiro Rolando \\ Vasconcellos $2 *$ \\ 12 Unigranrio - PPGEC \\ Rua Prof. José Herdy, 1160, \\ Duque de Caxias - RJ - Brasil \\ *roberta.vasconcellos@unigranrio.edu.br
}

\section{Resumo}

Embora seja pautada na distância física entre professor e alunos, a Educação a Distância substitui a lógica bidirecional pela multidirecional e exige a rápida adaptação de discentes e docentes ao uso das tecnologias que a cada dia são incorporadas a essa modalidade. Nesse cenário, faz-se necessário, cada vez mais, um profissional capaz de realizar a mediação entre o aluno e o conhecimento, de forma diferenciada e efetiva: o docente online. O presente artigo apresenta um produto educacional desenvolvido ao longo do curso de mestrado profissional na área de ensino de Ciências. Trata-se de recurso de design instrucional no formato de um mapa de atividades para elaboração futura de um curso de formação em docência online. Valendose da abordagem metodológica da pesquisa-ação, dezesseis docentes da Unigranrio evidenciaram elementos que contribuíram para a construção do produto como forma de intervenção para a melhoria do trabalho na EaD. Para a análise dos dados e para a elaboração do produto educacional aqui proposto, utilizou-se a análise de conteúdo na perspectiva de Bardin (2011). Foram realizados três encontros com os professores online, a fim de discutir e apresentar propostas para a problemática da formação continuada necessária para o fazer docente do tutor. Por meio do produto aqui desenvolvido foi possível visualizar todos os caminhos que deverão ser perpassados pelo docente online, de maneira que esse profissional possa mediar, acompanhar e avaliar a aprendizagem de forma autônoma. Os resultados demonstraram que há demandas específicas para a atuação do professor na modalidade a distância, e a criação de cursos de formação continuada para docentes online mostrou-se uma estratégia relevante para facilitar a compreensão do trabalho desempenhado por esse profissional.

Palavras-chave: Formação docente. Educação a Distância. Design instrucional. 


\section{A Proposal for Continuing Education Course for Online Teachers}

\section{Abstract}

Although Distance Education is based on the physical distance between teacher and students, it replaces bidirectional with multidirectional logic and it requires rapid adaptation of students and teachers to use the technologies that are incorporated into this modality each day. In this case, it is highly necessary a professional able to mediate student and knowledge, in a differentiated and effective way: the online teacher. This paper presents an educational product developed during the professional master's degree course in Science. This is an Instructional Design resource in the form of an Activity Map for future elaboration of an Online Teaching Training Course. Using the methodological approach of action research, sixteen professors from Unigranrio University showed elements that contributed to develop the product as a form of intervention to improve work in DE. For data analysis and for the elaboration of the educational product proposed here, we have used content analysis from the perspective of Bardin (2011). Three online meetings were held with teachers in order to discuss and present proposals for the subject of continuing education, essential to the tutor's work. Through the product developed it was possible to visualize all the paths that should be followed by the online teacher, so that this professional can mediate, monitor and evaluate learning autonomously. The results showed that there are specific demands for the teacher's performance in distance education and the creation of continuing education courses for online teachers proved to be a relevant strategy to facilitate the understanding of the work performed by this professional

Keywords: Online Teacher Training. Distance Education. Instructional Design.

\section{Introdução}

A necessidade de desenvolver um trabalho a fim de atender às demandas específicas da EaD, modalidade educacional em crescimento, amplia a procura por uma formação direcionada para docentes online. Embora seja pautada na distância física entre o professor e alunos, a EaD substitui a lógica bidirecional pela multidirecional e exige a rápida adaptação de discentes e docentes ao uso das tecnologias que, a cada dia, são incorporadas a essa modalidade.

Essa ótica pode ser ainda mais ampliada quando pensamos sobre a docência online em cursos de licenciatura. Afinal, os docentes online também serão responsáveis pela formação de "futuros" professores da Educação Básica que, em cadeia, também farão uso de diferentes estratégias educacionais utilizando tecnologias.

O docente online circula de modo diferenciado pelo espaço e tempo, utiliza tecnologias como suporte para o ensino, tem um aluno que recebe informações variadas na modernidade, promove a construção do saber, entre outras características. Nesse cenário se faz necessário, cada vez mais, um profissional capaz de realizar a mediação entre o aluno e o conhecimento, de forma diferenciada e efetiva. 
O artigo aqui apresentado foi elaborado no Programa de Pós-Graduação em Ensino das Ciências, com base na pesquisa intitulada Curso de Formação para Docência Online: uma proposta para a formação continuada. O produto final da pesquisa foi um mapa de atividades, um recurso de design instrucional (metodologia de planejamento pedagógico amplamente utilizada na EaD) que apresenta o roteiro do curso online produzido. Por meio dele, é possível visualizar a construção do conhecimento e todos os caminhos que deverão ser perpassados pelo cursista, oferecendo ao docente online subsídios para mediar, acompanhar e avaliar a aprendizagem (CHAMIQUE; FIGUEIREDO, 2013).

Além de ser um curso proposto por docentes para docentes baseado na experiência adquirida ao longo do tempo, o produto está apresentado num formato próprio para a construção de cursos a distância, familiarizando os docentes aos recursos utilizados em EaD e facilitando a execução desse curso por parte das unidades de ensino.

\subsection{A Educação a Distância}

A importância de discutir uma EaD que supere a barreira espaço-temporal, capaz de promover o diálogo e a construção de uma aprendizagem individual e coletiva apoiada nas tecnologias digitais em rede, é enfatizado por Silva (2007). Ao mesmo tempo, Sartori (2007) ressalta que, desde a Lei $n^{\circ} 9.394$, de dezembro de 1996, a EaD se insere como elemento da política educacional, passando a ser um forte componente da educação formal, deixando de ser apenas uma manobra emergencial. Desde então, a EaD tem, entre outros objetivos, possibilitar a democratização do acesso à educação e minimizar custos; uma mudança no paradigma educacional.

Juntamente com um bom projeto comunicativo e pedagógico, a EaD inaugura novas interfaces e práticas pedagógicas com regras claras de ação sobre o campo de conhecimento, potencializando o ato de ensinar e de aprender. Todas essas novas mudanças no ato de ensinar estendem-se aos profissionais envolvidos na EaD, principalmente ao papel do docente online. Se antes, no modelo presencial tradicional, existia apenas o professor como centro do processo de ensino-aprendizagem - paradigma mais tarde quebrado, agora o professor é convidado a assumir um papel de "animador da inteligência coletiva" (LÉVY, 2000, p. 157), imprimindo esforços para desenvolver estratégias didáticas inovadoras, visando ao desenvolvimento de competências com base em modelos de aprendizagem ativa e colaborativa.

O desenvolvimento de tecnologias digitais em rede, juntamente com a democratização da internet, ampliou as possibilidades para o desenvolvimento da EaD, favorecendo estudos e pesquisas sobre o tema. A partir daí, as relações entre o ensino e a aprendizagem foram sendo modificadas, possibilitando o (res) surgimento da Educação a Distância como modalidade capaz de desenvolver a capacidade intelectual dos indivíduos fora do cenário de sala de aula física. Nesse contexto, surge a cada dia uma série de novos instrumentos capazes de auxiliar esse processo pedagógico.

Um ponto muito relevante na trajetória da EaD é o ensino legalmente conhecido como "semipresencial". A Portaria n².253, de 18 de outubro de 2001 (BRASIL, 2001), revogada em 2004, determinava que a oferta das disciplinas não presenciais de um curso presencial poderia "incluir métodos e práticas de ensino-aprendizagem que incorporem o uso integrado de tecnologias de informação e comunicação para a realização dos objetivos pedagógicos" (Art. $2^{\circ}$ ).

A Portaria $n^{\circ}$ 4.059, de 10 de dezembro de 2004 (BRASIL, 2004), então, fundamentada no mesmo Art. 81 da Lei n 9.394/96, que tratava de cursos experimentais, substituía a expressão "não presencial" por "semipresencial", mantendo o máximo de $20 \%$ da carga horária total do curso para a oferta de disciplinas semipresenciais. 
Em 10 de outubro de 2016, por meio da Portaria n 1.134 (BRASIL, 2016) era autorizada a introdução, “na organização pedagógica e curricular de seus cursos de graduação presenciais regularmente autorizados, de disciplinas na modalidade a distância" (Art. $1^{\circ}$ ). A modalidade EaD poderia ser ofertada, "integral ou parcialmente, desde que essa oferta não ultrapassasse $20 \%$ (vinte por cento) da carga horária total do curso" (Art. $\left.1^{\circ}, \S 1^{\circ}\right)$.

A Portaria n 1.428, de 28 de dezembro de 2018 (BRASIL, 2018), estabelece que os cursos de graduação podem ofertar até $40 \%$ de suas disciplinas a distância, desde que os alunos fossem informados (com exceção dos cursos da área da Saúde e de Engenharia):

Art. $7^{\circ} \mathrm{A}$ oferta das disciplinas previstas nos Arts. $2^{\circ}$ e $3^{\circ}$ desta Portaria deverá incluir métodos e práticas de ensino-aprendizagem que incorporem o uso integrado de tecnologias de informação e comunicação - TIC para a realização dos objetivos pedagógicos, material didático específico, bem como a mediação de tutores e profissionais da Educação com formação na área do curso e qualificados em nível compatível ao previsto no projeto pedagógico do curso - PPC e no plano de ensino da disciplina, que deverão descrever as atividades realizadas a distância, juntamente com a carga horária definida para cada uma, explicitando a forma de integralização da carga horária destinada às atividades online.

Com efeito, a compreensão desse contexto permite-nos atribuir grande importância ao conhecimento das tecnologias digitais em rede e estabelecer novas propostas de ensino que impliquem ressignificar a docência. Para contemplar as diferentes possibilidades de utilização, é importante que fiquemos atentos a: diferentes mídias e/ou materiais; diversidade na abordagem cultural; objetividade nas informações; integração de várias linguagens: sons, texto, imagens, gráficos e mapas, entre outros; pesquisas que estimulem a construção do conhecimento (individual e coletivo). Esses itens podem ser apresentados como possibilidade de sucesso quando bem trabalhados; ou limites, caso não se tenha com cada um deles o devido cuidado.

A Educação a Distância é um meio de ampliar e aplicar novas oportunidades de acesso ao ensino e proporcionar modos de aprender variados para aqueles que almejam o desenvolvimento de habilidades e competências. Em Santos (2018), podemos ver o grande desafio da educação nos tempos atuais:

\footnotetext{
A formação na cultura digital tem sua especificidade, vivemos imersos em um contexto sociotécnico onde ciberespaço, mobilidade, ubiquidade, coautoria e aprendizagem colaborativa são algumas dentre as mais variadas noções que nos desafiam (p. 10).
}

Dessa forma, a EaD vem se reafirmando como modalidade de ensino, visando à formação de sujeitos ativos no processo de construção do conhecimento.

\subsection{A Formação Continuada de Professores e a EaD}

Embora seja pautada na distância física entre o professor e alunos, essa modalidade de ensino exige a adaptação de discentes e docentes ao uso das tecnologias que a cada dia são incorporadas à EaD; ou seja, há a necessidade constante de utilizar estratégias diferenciadas que fujam da tendência tradicional de ensino, uma vez que a aprendizagem não ocorre de uma só maneira. A cibercultura apresenta um leque de interfaces que podem contemplar diferentes aprendizagens, colaborando nesse sentido. Não pode- 
mos negar que essas mudanças precisam ser vistas como reais, pois já fazem parte do nosso cotidiano e precisam ser incorporadas às nossas vivências como professores e alunos.

Moran (2013, p. 63) destaca que

a Educação a Distância está modificando todas as formas de ensinar e aprender, inclusive as presenciais, que começam a utilizar cada vez mais metodologias semipresenciais, flexibilizando a necessidade de presença física, reorganizando os espaços e os tempos, as mídias, as linguagens e os processos.

Na sociedade da informação, estamos reaprendendo a conhecer, a nos comunicar, a ensinar; reaprendendo a integrar o humano e o tecnológico; a integrar o individual, o grupal e o social (MORAN, 2013).

O uso das tecnologias na educação é uma realidade a ser enfrentada e explorada; não pode ser encarada como modismo ou prática destinada a alguns professores. Precisamos avançar e adaptar programas e currículos dos cursos ao cotidiano vivido por nossos alunos, buscando criar comunidades de aprendizagem e de investigação que envolvam e incentivem os alunos à autonomia e à busca por saberes.

Para que possamos ser bem-sucedidos nessa tarefa, é preciso que o professor direcione seus alunos. Freire (2002) diz que o educador não pode negar-se o dever de, na sua prática docente, reforçar a capacidade crítica do educando, sua curiosidade, sua insubmissão.

A grande quantidade de informações disponíveis na internet à disposição de todos não é capaz, por si só, de auxiliar os alunos em sua caminhada rumo ao conhecimento. Nesse cenário, faz-se necessário um profissional capaz de realizar a mediação entre o aluno e o conhecimento de forma diferenciada e efetiva: o docente online, muitas vezes chamado de tutor. Esse profissional deve ser capaz de promover o diálogo com e entre os alunos, orientando-os no processo de aprendizagem mediado pelas tecnologias. Silva (2009, p. 5) destaca:

o papel do professor é redirecionado para facilitar os percursos de aprendizagem dos alunos nos ambientes digitais. Assim, os docentes atuam diretamente na troca e na construção mútua de fluxos de informação, visando à transformação da simples informação em conhecimento. Esse é o grande desafio da educação na era tecnológica: como ensinar os alunos a aprender de forma autônoma, descobrindo a importância de produzir conhecimento a partir do turbilhão digital e do universo oceânico de informações disponível no ciberespaço.

Assim, o docente online passa a ser visto como um sujeito que participa ativamente da prática pedagógica (mediador pedagógico), e não como mero "transmissor de informações". Para Machado e Machado (2004, p. 5),

o papel do professor como repassador de informações deu lugar a um agente organizador, dinamizador e orientador da construção do conhecimento do aluno e até da sua autoaprendizagem. Sua importância é potencializada e sua responsabilidade social, aumentada.

Exatamente por ser um docente que circula de modo diferenciado pelo espaço e tempo, por utilizar tecnologias como suporte para o ensino, por ter um aluno que absorve informações várias na moderni- 
dade, por promover a construção do saber, entre outras características, é que o docente online precisa desempenhar funções que vão além do lecionar.

De acordo com Esquincalha (2009, p. 10),

o tutor trabalha como um mediador do processo de ensino-aprendizagem, orientando e direcionando as discussões [...] e atuando como motivador, instigando a curiosidade e o desejo do estudante em aprender [...] por meio da interação e trocas de ideias entre todos no fórum.

A postura do educador deve ser dirigida para o trabalho em parceria com o estudante, orientando-o para o diálogo, o trabalho em projetos e a aprendizagem pela pesquisa, pois somente por meio de trocas dialógicas é que se chega ao conhecimento. Estimular o companheirismo, a afetividade, a empatia, a sinergia, a partilha do conhecimento é ensinar o discente a caminhar nessa nova etapa da sua história (NOBRE; MELO, 2011).

Nesse contexto, não podemos deixar de destacar a importância da formação necessária ao professor docente online. Gatti (2009, p. 2) destaca que

\begin{abstract}
no caso dos processos de educação a distância observa-se a importância do professor, desde a criação/produção/revisão/recomposição dos materiais didáticos até os contatos com os alunos, mais diretos ou indiretos, em diferentes momentos, por diferentes modalidades: na colocação de temas, de problemas, em consultas, em tutoria, em revisões, em processos de recuperação etc.; por e-mails, por webcam, por telefone, em bases de atendimento etc.
\end{abstract}

A análise desse contexto e os desafios propostos a esse docente revelam que é preciso apontar que tipo de competências esse professor docente online precisa para a realização da docência em EaD. Bernardino (2011) aponta que o professor deve possuir três dimensões de competências: técnica, gerencial e pedagógica.

1. Dimensão técnica Nesta dimensão, o professor deve possuir: o domínio dos recursos tecnológicos; o interesse em busca de novas ferramentas que contribuam para o processo de ensino-aprendizagem e o domínio de procedimentos para a confecção de relatórios técnicos;

2. Dimensão gerencial Nesta dimensão, o professor deve ser capaz de planejar prazos; reformular estratégias e solucionar problemas; ter autonomia na tomada de decisões e capacidade para mediação de conflitos.

3. Dimensão pedagógica Nesta dimensão, o professor deve: incentivar a busca de respostas pelos alunos; ter disposição e vontade para continuar aprendendo; domínio de técnicas motivacionais aplicáveis à EaD; conhecer e utilizar recursos didáticos disponíveis; compreender os critérios e as perspectivas da avaliação, e planejar e elaborar materiais didáticos.

Ainda pensando nessa "competência" do docente online, as Referências de Qualidade para Educação Superior a Distância (2007) indicam que as instituições de ensino devem incluir em seus projetos pedagógicos cursos de capacitação e avaliação permanente dos docentes que compõem a equipe multidisciplinar dos cursos de modalidade a distância, esclarecendo que não há um modelo único; ou seja, cada programa de cada instituição apresenta diferentes desenhos e múltiplas combinações de linguagens, estratégias educacionais e mecanismos tecnológicos. 
Um profissional tão diferenciado e cada vez mais solicitado, capaz de tantos conhecimentos teóricos, técnicos, além de inteligência emocional, necessita ser valorizado, o que infelizmente não se constata quando analisadas sua carga horária, a quantidade de horas extras trabalhadas sem remuneração, e o salário, quando comparados aos do professor do ensino presencial.

\subsection{O Design Instrucional}

A discussão sobre o design instrucional dos cursos a distância mostra-se no panorama descrito acima como um tema de grande importância para o cenário educacional, visto que é a partir do design instrucional que se pensa, organiza e cria qualquer curso ofertado na modalidade online da EaD.

O curso de formação online pensado como produto desta pesquisa foi planejado para a atuação docente, com material direcionado às práticas educacionais. Sendo assim, foi/é de extrema importância o papel do designer instrucional ao escolher a equipe necessária e os profissionais capacitados, selecionar os melhores e mais adequados recursos para as atividades propostas, bem como as avaliações no decorrer do curso.

Ao planejar, elaborar e acompanhar um curso virtual, esse profissional tem como objetivo facilitar a construção do conhecimento e aprendizagem do aluno, tendo como preocupação uma formação holística do docente online na instituição de ensino, compreendendo seu papel fundamental e o melhor modo de apresentar as instruções e o conteúdo.

A utilização da ferramenta mapa de atividades proporciona à equipe multidisciplinar uma visão geral e, ao mesmo tempo, detalhada, das peculiaridades do curso e do público-alvo. A grande quantidade de possibilidades pedagógicas apresentadas pelos ambientes virtuais de aprendizagem (AVA) permite a construção de planejamentos diversificados que propiciem a flexibilidade para o estudo. Os modelos pedagógicos tradicionais vêm sendo substituídos em virtude do grande desenvolvimento tecnológico, assim como as novas propostas pedagógicas propõem uma aprendizagem coletiva e contínua (SILVA, 2009).

Em síntese, o trabalho do designer instrucional para a EaD online vai além do uso isolado de recursos diversificados e do pensar instrumental ou técnico; ou seja, possibilita uma aprendizagem com base na criatividade e na autonomia. Entre os produtos criados pelo designer instrucional podemos citar os modelos do plano de ensino/curso/treinamento, roteiros de conteúdo para a mídia impressa, mapas conceituais da disciplina/curso, desenho do ambiente de aprendizagem, roteiros para elaboração de vídeos, áudios, histórias em quadrinhos e animações e checklists de validação de conteúdos (BARREIRO, 2016).

Para o designer instrucional, conhecer diferentes abordagens pedagógicas com foco na aprendizagem online, além de técnicas de avaliação individuais e em grupo e os tipos de comunicação existentes, a afetividade e a influência desses aspectos na aprendizagem do aluno são de fundamental importância. No design instrucional existem diferentes modelos, mas, segundo Filatro (2008), "é o modelo Addie o mais difundido", abrangendo cinco fases distintas:

1. Analysis análise;

2. Design desenho;

3. Development desenvolvimento;

4. Implementation implementação;

5. Evaluation avaliação.

O mapa de atividades é um recurso do modelo Addie, elaborado na fase número 2 - Design. Em qualquer uma dessas ações que utilizem o modelo Addie, "planejar" é o passo fundamental. Filatro (2004) des- 
taca a relevância do design instrucional como ação intencional e sistemática que envolve o planejamento, o desenvolvimento e a utilização de métodos, técnicas, atividades, materiais e artefatos educacionais em situações didáticas, a fim de motivar e envolver o aluno, potencializando sua construção de conhecimento. É importante considerar todas as variáveis necessárias à formação do aluno, a fim de adaptar o sistema de aprendizagem aos estudantes, e não o contrário.

\section{Metodologia}

Para o desenvolvimento da pesquisa e construção do produto, optou-se por uma pesquisa de caráter qualitativo, na qual o pesquisador procura compreender algum tipo de fenômeno, segundo a perspectiva dos participantes da situação estudada para, baseado nessas informações, apresentar sua interpretação.

Nessa perspectiva, escolheu-se a pesquisa-ação educacional por se tratar de uma metodologia que permite que os próprios professores e pesquisadores possam utilizar suas experiências como fonte para aprimorar o ensino e, consequentemente, o aprendizado. A partir de elementos evidenciados por docentes online da Unigranrio, foi proposto o Curso de Formação Online em Docência Online como forma de intervenção, com base no Mapa de Atividades.

A pesquisa desenvolveu-se na Unigranrio - importante instituição de ensino superior, com sede em Duque de Caxias, na Baixada Fluminense, com dezesseis professores online escolhidos aleatoriamente. Desses, onze são especialistas e cinco são mestres. Oito professores são especialistas em EaD ou em áreas afins, dois em Docência no Ensino Superior e seis sem especialização na área, todos com cursos de extensão na área de Educação a Distância.

Foram realizadas três reuniões para elaboração e validação do produto educacional. Esses momentos foram utilizados para estudar as estratégias de enfrentamento de que dispõem os docentes online para desenvolver seu trabalho. Utilizaram-se diferentes fontes de dados e perspectivas teóricas para o estudo desses fenômenos.

Para a análise dos dados coletados ao longo da pesquisa, utilizou-se a Análise de Conteúdo na perspectiva de Bardin (2011). Trata-se de um conjunto de técnicas de análise da comunicação que têm o objetivo de descrever o conteúdo das mensagens, baseadas em procedimentos predeterminados e objetivos. Para a análise dos dados, conforme orientado no método de pesquisa escolhido, foi realizada a pré-análise, a exploração do material e o tratamento dos resultados:

1. Na pré-análise são selecionados os documentos a serem analisados e formuladas as hipóteses para a elaboração de indicadores para a interpretação final. Esse primeiro momento se refere à reunião inicial, a partir dos apontamentos registrados das falas dos docentes online e da análise do questionário.

2. Na fase de exploração do material codificam-se os dados, transformando-os em unidades, para determinar as categorias, agrupando os pensamentos citados com maior frequência, a partir de características comuns. Por meio dessa estratégia foi possível elencar os módulos do curso a ser desenvolvido, atendendo às necessidades mais recorrentes que apareceram durante a primeira reunião.

3. No tratamento dos resultados foram feitas inferências e interpretações. Esse procedimento foi ao encontro da segunda e da terceira reuniões, num movimento de troca para análise e validação do produto. 


\section{Resultados e Discussão}

Com relação à experiência, todos os participantes possuem mais de um ano como docente online; a maioria deles $(68,75 \%)$ desempenha essa atividade há 4 a 6 anos. Em relação à experiência como docente do ensino superior em cursos presenciais, $25 \%$ dos participantes nunca trabalharam nesta modalidade de ensino; 75\% dos professores possuem experiência com cursos presenciais, sendo 18,75\% deles entre 7 e 10 anos de atividades nessa modalidade.

Essas informações iniciais demonstram que os participantes puderam contribuir de maneira efetiva para a elaboração de um curso de formação continuada online para docentes online, uma vez que tanto a formação quanto o tempo de trabalho na área se apresentam de maneira consolidada.

Quando perguntados sobre a oferta de cursos de formação para docentes online no início de suas atividades nas instituições de ensino em que trabalham ou já trabalharam, 56,25\% dos docentes responderam que tiveram essa oportunidade. Embora seja a maioria, o número de docentes que não teve tal opção foi alto: $43,75 \%$.

Frente a essa constatação, foram questionados, de acordo com a experiência de cada um, se a oferta de um curso de formação em docência online ajudaria no desenvolvimento de suas atividades como professor; quase que por unanimidade $(93,75 \%)$ responderam que sim. Apenas um docente respondeu que não; quando analisamos o porquê, percebemos que ele afirma que em início de carreira essa estratégia se faz necessária:

No atual momento não preciso, mas no começo sim, teria sido muito útil (Participante 7).

Vemos que, mesmo sendo uma ação proposta por algumas instituições de ensino, grande parte dos atores envolvidos na pesquisa não participou de iniciativas de formação continuada para EaD, e todos afirmam se tratar de uma ação válida e necessária.

Quando perguntados por que um curso de formação em docência online ajudaria no desenvolvimento de suas atividades como professor, os participantes indicaram que por meio desse curso é possível:

I. Criar uma identidade para a instituição em relação ao padrão de atendimento;

II. Desenvolver a autonomia do professor;

III. Diferenciar a EaD do modelo presencial;

IV. Atualizar o professor;

V. Agilizar o atendimento ao aluno;

VI. Desenvolver habilidades técnicas para navegação no AVA; e

VII.Desenvolver habilidades pedagógicas para mediação com os alunos.

Essas foram as respostas recorrentes. Um dos participantes afirmou que um curso como o sugerido ajuda nas atividades docentes, pois foi por meio dele que conseguiu iniciar sua carreira.

Todos os participantes citaram pontos positivos em relação à oferta do curso. Alguns destacaram que, embora necessário 
Poucos cursos realmente acrescentam pedagogicamente à formação do tutor. Só acredito em cursos que trabalhem metodologia do ensino superior (se for o caso de universidade), metodologia científica e mediação. Depois da parte teórica, o tutor só deveria estar habilitado se fosse acompanhado em uma turma teste por um mentor. Essa prática é muito significativa para um alinhamento de ações (Participante 5).

O curso oferecido na última instituição em que trabalhei era muito incipiente e não passava nada do que ocorria durante a prática cotidiana. Faltavam noções de como lidar com o aluno, como tratar algumas questões básicas etc. Era apenas uma "olhada" no ambiente. Depois disso, o ambiente se modificou mais duas vezes e o processo foi o mesmo. Os professores EaD foram descobrindo as plataformas com o uso (Participante 12).

Como se pode observar, não se trata apenas da oferta, mas o cuidado em contemplar a maioria dos possíveis pontos de tensão que o docente online encontrará na sua prática.

Foi solicitado, também, que os docentes online elencassem os principais temas que deveriam ser abordados assim que uma instituição de ensino superior contratasse um docente online. Após a análise das respostas, criaram-se as seguintes categorias:

I. Estratégias de interação e mediação;

II. Como elaborar materiais: vídeos, apresentações;

III. Como elaborar atividades para a EaD;

IV. Navegação no AVA e funcionalidades do sistema;

V. Atribuições do professor online;

VI. Netiqueta; e

VII.Regimento interno da instituição.

Podemos perceber que a maior parte da preocupação dos docentes online foi com a qualidade do trabalho a ser desenvolvido, ao listar principalmente temas que contemplassem uma forma de se comunicar melhor e atingir a aprendizagem dos alunos. Como afirma Pedrosa (2003, p. 11),

Há necessidade de uma seleção de atividades e interações, com a escoIha de situações e exemplos significativos, estruturando-os numa sequência lógica, de modo que não se restrinjam à observação e assimilação de conteúdos, mas que instiguem a atuação e a investigação.

Ao encontro desse levantamento, é necessário levar em consideração o conceito de competência profissional apresentado por Santos et al. (2005, p. 2):

em síntese, vê-se que o conceito de competência assume múltiplas significações. Porém, em termos gerais, este pode ser compreendido como um conhecimento orientado para a ação, cuja compreensão prescinde de sua inserção contextual, ou ainda uma combinação de conhecimentos, de saber-fazer, de experiências e comportamentos que se exercem em um contexto preciso. 
Para finalizar a primeira reunião, foi sugerido que os participantes da pesquisa relatassem suas principais dificuldades ao ingressar na carreira de docente online e quais estratégias utilizaram para superar as dificuldades apresentadas.

Em seu artigo, referindo-se a Zafirian (2001), Santos et al. (2005) apresentam as competências partindo de três eixos: biografia e socialização; formação educacional; e experiência profissional. As respostas que encontramos ao longo dessa etapa evidenciaram as diferentes competências que os docentes online destacam para o fazer do docente online, num movimento de pensar e repensar a sua própria prática. A partir disso, obtivemos importantes indicações que apontam para uma formação contemplando os eixos indicados por Santos et al. (2005).

A partir da questão "Relate suas principais dificuldades ao ingressar na carreira de docente online", encontraram-se 28 apontamentos. Para análise, buscou-se relacioná-los às categorias criadas com base nos temas que devem fazer parte do curso, propostos pelos próprios professores. Assim, os resultados foram:

I. Estratégias de interação e mediação: $25 \%$;

II. Como elaborar materiais: vídeos, apresentações: 17,86\%;

III. Como elaborar atividades para a EaD: 14,29\%;

IV. Navegação no AVA e funcionalidades do sistema: 10,71\%;

V. Atribuições do professor online: 10,71\%;

VI. Netiqueta: $0 \%$;

VII.Regimento interno da instituição: 14,29\%;

VIII. Não teve dificuldades: 7,14\%.

Considerando a questão “Cite estratégias que utilizou para superar as dificuldades apresentadas na questão anterior", as respostas dividiram-se de acordo com as estratégias utilizadas. Foram 19 apontamentos:

I. Formação: 26,32\%;

II. Desenvolvendo estratégias de interação e mediação: 26,32\%;

III. Troca de experiência com seus pares: 15,79\%;

IV. Experiência própria: 15,79\%;

V. Treinamento: $10,53 \%$;

VI. Não teve dificuldade: 5,27\%.

A experiência profissional dos docentes online entrevistados possibilitou que eles traçassem estratégias que permitiram superar situações de crise. Momentos que possibilitam a troca entre os professores, sejam presenciais - reuniões, grupos de estudo - ou online - fóruns, grupos de WhatsApp - são importantes espaços que facilitam o desenvolvimento das atividades. Conforme afirma Pedrosa (2003, p. 8), “a prática pedagógica e a experiência profissional acumuladas por professores ao longo de suas vivências indicam que a universidade também tem muito a aprender com eles".

Após a análise de todos os apontamentos da primeira reunião, foi possível transformar esses dados em unidades e estabelecer as categorias para possíveis temas indispensáveis ao curso de formação - produto desta pesquisa -, agrupando os pensamentos citados com maior frequência, a partir de características comuns. Assim, foi possível elencar os módulos do curso a ser desenvolvido, atendendo às necessidades mais recorrentes que apareceram durante a primeira reunião. 
Dessa forma, o mapa de atividade de design instrucional foi criado para o Curso de Formação Online para Docente Online. Para esse curso, foi proposta a carga horária de 40 horas no decorrer de quatro semanas, o que convida o professor a uma média de dez horas de estudo por semana. O curso está baseado na teoria pedagógica do sociointeracionismo (VIGOTSKY, 1991).

Para Vygotsky, o desenvolvimento do ser humano implica transformações qualitativas do pensamento, reconhecendo o papel da relação entre o indivíduo e a sociedade. Pautado numa visão socioconstrutivista do desenvolvimento, com destaque para o ambiente social na aprendizagem, a teoria do psicólogo afirma que a aprendizagem se dá em colaboração com o outro. Na Educação a Distância fundamentada em uma proposta sociointeracionista, é preciso considerar que o professor deve assumir o papel de arquiteto, observador e desafiador desse desenvolvimento, isso é, de mediador. A seguir está o mapa de atividades criado.

Quadro 1 - Produto: Mapa de Atividades de Design Instrucional do Curso de Formação para Docente Online

\begin{tabular}{|c|c|c|c|c|c|}
\hline $\begin{array}{c}\text { Aula/ } \\
\text { semana } \\
\text { (período) }\end{array}$ & $\begin{array}{l}\text { Unidade } \\
\text { (tema } \\
\text { principal) }\end{array}$ & $\begin{array}{l}\text { Subunidades } \\
\text { (subtemas) }\end{array}$ & Objetivos específicos & $\begin{array}{c}\text { Atividades teóricas } \\
\text { e mídias/ferramentas } \\
\text { de EaD }\end{array}$ & $\begin{array}{c}\text { Atividades práticas } \\
\text { e mídias/ferramentas } \\
\text { de EaD }\end{array}$ \\
\hline $\begin{array}{l}\text { Aula } 1 \\
10 \mathrm{~h} \\
7 \text { dias }\end{array}$ & $\begin{array}{l}\text { Sou } \\
\text { professor } \\
\text { online e } \\
\text { agora? }\end{array}$ & $\begin{array}{l}\text { - O que é EaD; } \\
\text { - Regulamentação } \\
\text { da EaD; } \\
\text { - Referenciais de } \\
\text { Qualidade da EaD; } \\
\text { - Atribuições do } \\
\text { professor online; } \\
\text { - A instituição de } \\
\text { ensino; } \\
\text { - Regimento inter- } \\
\text { no da instituição }\end{array}$ & $\begin{array}{l}\text { - Distinguir os principais } \\
\text { conceitos relacionados } \\
\text { à EaD; } \\
\text { - Analisar documentos } \\
\text { que amparam a EaD no } \\
\text { Brasil; } \\
\text { - Conhecer a instituição } \\
\text { e seu regimento interno; } \\
\text { - Apreciar as atribuições } \\
\text { do professor online; } \\
\text { - Discutir sobre o papel } \\
\text { da EaD frente à educa- } \\
\text { ção nos dias de hoje. }\end{array}$ & $\begin{array}{l}\text { Atividade 2: Leitura do texto } \\
\text { “Educação a Distância em } \\
\text { Foco" } \\
\text { Ferramenta: Página } \\
\text { Mídia: Link para texto elabo- } \\
\text { rado para o curso. } \\
\text { Atividade 3: Leitura dos } \\
\text { “Referenciais de Qualidade } \\
\text { da EaD” } \\
\text { Ferramenta: Arquivo } \\
\text { Mídia: Texto PDF } \\
\text { http://portal.mec.gov.br/ } \\
\text { seed/arquivos/pdf/legisla- } \\
\text { cao/refead1.pdf } \\
\text { Número de páginas: } 31 \\
\text { Atividade 4: Assistir ao } \\
\text { vídeo: Um Olhar Estratégico } \\
\text { Sobre o Novo Marco Regula- } \\
\text { tório da EAD." } \\
\text { Ferramenta: Página } \\
\text { Mídia: Vídeo - Link: } \\
\text { https://www.facebook.com/ } \\
\text { AbedAssociacaoBrasileira- } \\
\text { DeEducacaoADistancia/vide- } \\
\text { os/1459254577536291/ } \\
\text { Duração: } 29: 01 \text { min } \\
\text { Atividade 6: Leitura do texto } \\
\text { “Conhecendo a UNIGRAN- } \\
\text { RIO" } \\
\text { Ferramenta: Página } \\
\text { Mídia: Link para texto elabo- } \\
\text { rado para o curso }\end{array}$ & $\begin{array}{l}\text { Atividade 1: Fórum } \\
\text { de apresentação dos } \\
\text { participantes do curso. } \\
\text { Ferramenta: Fórum - } \\
\text { Avaliativa: Não } \\
\text { (DIAGNÓSTICA) } \\
\text { Duração: } 7 \text { dias } \\
\text { Atividade 5: Fórum de } \\
\text { discussões sobre EaD: } \\
\text { “Qual é o papel da EaD } \\
\text { frente à educação nos } \\
\text { dias de hoje?". } \\
\text { Ferramenta: Fórum } \\
\text { Avaliativa: Sim } \\
\text { (SOMATIVA) } \\
\text { Valor: } 1 \text { Peso: } 1 \\
\text { Duração: } 7 \text { dias }\end{array}$ \\
\hline
\end{tabular}




\begin{tabular}{|c|c|c|c|c|c|}
\hline $\begin{array}{c}\text { Aula } 2 \\
10 \mathrm{~h} \\
7 \text { dias }\end{array}$ & $\begin{array}{l}\text { Estraté- } \\
\text { gias de } \\
\text { interati- } \\
\text { vidade e } \\
\text { mediação }\end{array}$ & $\begin{array}{l}\text { - A interatividade e } \\
\text { a mediação na EaD; } \\
\text { - Netiqueta; } \\
\text { - A evasão na EaD }\end{array}$ & $\begin{array}{l}\text { - Valorizar práticas que } \\
\text { reconheçam a intera- } \\
\text { tividade como fator } \\
\text { essencial na docência } \\
\text { online. } \\
\text { - Selecionar iniciativas } \\
\text { assertivas no combate à } \\
\text { evasão dos alunos. } \\
\text { - Apreciar boas } \\
\text { práticas em EaD. }\end{array}$ & $\begin{array}{l}\text { Atividade 7: Assistir ao } \\
\text { vídeo “Interatividade na } \\
\text { Educação - profo Dr. Marco } \\
\text { Silva” } \\
\text { Ferramenta: Página } \\
\text { Mídia: Vídeo - Link: https:// } \\
\text { www.youtube.com/watch?- } \\
\text { V=shrodbkfij0 } \\
\text { Duração: 09:19 min } \\
\text { Atividade 8: Assistir a } \\
\text { animação “Docência em EaD } \\
\text { - Netiqueta” } \\
\text { Ferramenta: Página } \\
\text { Mídia: Vídeo - Link: } \text { https:// } \\
\text { www.youtube.com/watch?- } \\
\text { V=zbeXkKcgnwE } \\
\text { Duração: 02:26 min } \\
\text { Atividade 10: Leitura do } \\
\text { artigo “A Evasão na EaD: } \\
\text { Investigando Causas, } \\
\text { Propondo Estratégias.” } \\
\text { Ferramenta: Página } \\
\text { Mídia: Arquivo PDF http:// } \\
\text { revistas.utp.ac.pa/index.php/ } \\
\text { clabes/article/view/865/892 } \\
\text { Número de páginas: } 8 \\
\text { Atividade 11: Leitura do } \\
\text { infográfico “Guia de Boas } \\
\text { Práticas em EaD”. } \\
\text { Ferramenta: Página } \\
\text { Mídia: Link para a imagem } \\
\text { disponível em: } \\
\text { https://br.pinterest.com/ } \\
\text { pin/331859066274224245/ } \\
\text { Atividade 12: Leitura da } \\
\text { reportagem “No Dia do Pro- } \\
\text { fessor, youTubers ensinam } \\
\text { como gravar video-aulas". } \\
\text { Ferramenta: Página } \\
\text { Mídia: Link para a imagem } \\
\text { disponível em: } \\
\text { http://g1.globo.com/edu- } \\
\text { cacao/noticia/2015/10/ } \\
\text { no-dia-do-professor-youtu- } \\
\text { bers-ensinam-como-gravar- } \\
\text { videoaulas.html }\end{array}$ & $\begin{array}{l}\text { Atividade 9: Fórum de } \\
\text { discussões sobre intera- } \\
\text { tividade e mediação: "As } \\
\text { interfaces disponíveis } \\
\text { no AVA garantem que a } \\
\text { aprendizagem ocorra de } \\
\text { forma colaborativa?". } \\
\text { Ferramenta: Fórum - } \\
\text { Avaliativa: Sim } \\
\text { (SOMATIVA) } \\
\text { Valor: } 2 \text { Peso: } 1 \\
\text { Duração: } 7 \text { dias } \\
\text { Atividade 13: Contrução } \\
\text { de uma Wiki: "Práticas } \\
\text { que ajudam a diminuir } \\
\text { a evasão nos ambientes } \\
\text { online". } \\
\text { Ferramenta: Wiki } \\
\text { Avaliativa: Sim (SOMA- } \\
\text { TIVA) } \\
\text { Valor: } 1 \text { Peso: } 1 \\
\text { Duração: } 7 \text { dias }\end{array}$ \\
\hline
\end{tabular}




\begin{tabular}{|c|c|c|c|c|c|}
\hline $\begin{array}{l}\text { Aula } 3 \\
1 \\
\text { encontro } \\
\text { presen- } \\
\text { cial (5h) } \\
5 \mathrm{~h} \text { à } \\
\text { distância } \\
7 \text { dias }\end{array}$ & $\begin{array}{l}\text { Navega- } \\
\text { ção no } \\
\text { AVA e } \\
\text { funciona- } \\
\text { lidades do } \\
\text { sistema }\end{array}$ & $\begin{array}{l}\text { - Navegação e } \\
\text { funcionalidades do } \\
\text { AVA da IE; } \\
\text { - Interfaces para } \\
\text { mediação e ava- } \\
\text { liação; } \\
\text { - Ferramentas de } \\
\text { gestão. }\end{array}$ & $\begin{array}{l}\text { • Experimentar os prin- } \\
\text { cipais recursos disponí- } \\
\text { veis no AVA da IE; } \\
\text { - Analisar as diferentes } \\
\text { interfaces para media- } \\
\text { ção e avaliação; } \\
\text { • Utilizar as ferramentas } \\
\text { de gestão disponíveis } \\
\text { para o professor online. }\end{array}$ & $\begin{array}{l}\text { Atividade 15: Assistir ao } \\
\text { vídeo "tutoriais para a utiliza- } \\
\text { ção do AVA" } \\
\text { Ferramenta: página } \\
\text { Mídia: vídeo - link para o ví- } \\
\text { deo elaborado para o curso. } \\
\text { Duração: a verificar. } \\
\text { Atividade 16: Leitura do tex- } \\
\text { to "tutoriais para a utilização } \\
\text { do AVA" } \\
\text { Ferramenta: página } \\
\text { Mídia: link para texto elabo- } \\
\text { rado para o curso. }\end{array}$ & $\begin{array}{l}\text { Atividade 14: Encon- } \\
\text { tro Presencial para a } \\
\text { apresentação do AVA da } \\
\text { instituição de ensino. } \\
\text { Ferramenta: Encontro } \\
\text { Presencial no labora- } \\
\text { tório. } \\
\text { Avaliativa: Sim } \\
\text { Avaliativa: Sim (SOMA- } \\
\text { TIVA) } \\
\text { Valor: } 2 \text { Peso: } 1 \\
\text { Duração: } 7 \text { dias } \\
\text { Atividade 17: Criação } \\
\text { de uma FAQ: “Principais } \\
\text { dúvidas sobre navega- } \\
\text { ção e funcionalidades } \\
\text { do AVA”. } \\
\text { Ferramenta: Glossário } \\
\text { Avaliativa: Sim } \\
\text { Avaliativa: Sim (SOMA- } \\
\text { TIVA) } \\
\text { Valor: } 1 \text { Peso: } 1 \\
\text { Duração: } 7 \text { dias }\end{array}$ \\
\hline $\begin{array}{c}\text { Aula } 4 \\
10 \mathrm{~h} \\
7 \mathrm{dias}\end{array}$ & $\begin{array}{l}\text { Como } \\
\text { elaborar } \\
\text { ativida- } \\
\text { des para } \\
\text { a EaD. }\end{array}$ & $\begin{array}{l}\text { - Desenho e } \\
\text { Planejamento de } \\
\text { Atividades na EaD; } \\
\text { - Avaliação; } \\
\text { - Plágio. }\end{array}$ & $\begin{array}{l}\text { - Compreender o pro- } \\
\text { cesso de planejamento } \\
\text { de atividades na EaD; } \\
\text { - Reconhecer recursos e } \\
\text { estratégias que podem } \\
\text { ser utilizados no design } \\
\text { da avaliação em EaD; } \\
\text { - Identificar situaçações } \\
\text { em que o plágio pode } \\
\text { ocorrer; } \\
\text { - Selecionar uma } \\
\text { ferramenta disponível } \\
\text { no Ambiente Virtual } \\
\text { de aprendizagem em } \\
\text { prol de uma educação } \\
\text { colaborativa; } \\
\text { - Gravar um vídeo de } \\
\text { orientação para uma } \\
\text { atividade. }\end{array}$ & $\begin{array}{l}\text { Atividade 17: Leitura do tex- } \\
\text { to "Desenho e Planejamento } \\
\text { de Atividades Didáticas em } \\
\text { Educação a Distância" } \\
\text { Ferramenta: Página } \\
\text { Mídia: Arquivo PDF http:// } \\
\text { www.cead.ufjf.br/wp-con- } \\
\text { tent/uploads/2015/05/me- } \\
\text { dia_biblioteca_desenho_pla- } \\
\text { nejamento.pdf } \\
\text { Número de páginas: } 15 \\
\text { Atividade 18: Assistir ao ví- } \\
\text { deo: "avaliação em educação } \\
\text { a distância” } \\
\text { Ferramenta: página } \\
\text { Mídia: vídeo - link: https:// } \\
\text { www.youtube.com/watch?- } \\
\text { v=ihl6hvllcju } \\
\text { Duração: } 23: 41 \text { min } \\
\text { Atividade 19: Leitura do } \\
\text { artigo “Nem tudo que parece } \\
\text { é: entenda o que é plágio". } \\
\text { Ferramenta: Página } \\
\text { Mídia: Arquivo PDF http:// } \\
\text { www.noticias.uff.br/arqui- } \\
\text { vos/cartilha-sobre-plagio-a- } \\
\text { cademico.pdf } \\
\text { Número de páginas: } 6\end{array}$ & $\begin{array}{l}\text { Atividade 20: Constru- } \\
\text { ção de uma atividade } \\
\text { colaborativa (na área } \\
\text { de conhecimento do } \\
\text { professor online). } \\
\text { Ferramenta: Tarefa } \\
\text { Avaliativa: Sim (SOMA- } \\
\text { TIVA) } \\
\text { Valor: } 1 \text { Peso: } 1 \\
\text { Duração: } 7 \text { dias } \\
\text { Atividade 21: Grava- } \\
\text { ção de um vídeo com } \\
\text { as orientações para a } \\
\text { realização da atividade } \\
\text { proposta na atividade } 20 . \\
\text { Ferramenta: Tarefa } \\
\text { Avaliativa: Sim (SOMA- } \\
\text { TIVA) } \\
\text { Valor: } 2 \text { Peso: } 1 \\
\text { Duração: } 7 \text { dias } \\
\text { Atividade 22: Questio- } \\
\text { nário de autoavaliação } \\
\text { Ferramenta: Tarefa } \\
\text { Avaliativa: Não (FOR- } \\
\text { MATIVA) } \\
\text { Duração: } 5 \text { dias }\end{array}$ \\
\hline
\end{tabular}

Interfaces como fórum, wiki, FAQ e produções de vídeo possibilitam a construção de atividades de cunho colaborativo, de maneira assíncrona, propiciando encontros virtuais para discussões e/ou detalhamento de conteúdo. Partindo de uma visão sociointeracionista, acredita-se que, para o desenvolvimento de projetos em EaD que favoreçam transformações qualitativas do pensamento, é indispensável a colaboração com o outro.

Para contemplar as diferentes possibilidades de utilização das ferramentas disponíveis no AVA, é importante o desenvolvimento de atividades que contemplem: ligação com novos sites e arquivos; diferentes mídias e/ou materiais; diversidade na abordagem cultural; objetividade nas informações; integração de várias linguagens: sons, texto, imagens, pesquisas que estimulem a construção do conhecimento (individual e coletivo). 
Em nosso último encontro, realizado no dia 4 de dezembro de 2018, os docentes online analisaram o mapa de atividades pela segunda vez e avaliaram a proposta de curso online, como forma de validar o produto. Todas as respostas afirmam que:

I. O programa do curso desenvolvido atende às necessidades dos docentes online levantadas durante a pesquisa;

II. Houve sequência no desenvolvimento do assunto de modo a facilitar o entendimento por parte do cursista;

III. A seleção de material didático e recursos utilizados no curso foi satisfatória, qualitativa e quantitativamente;

IV. O curso atendeu às expectativas, alcançando os seus objetivos propostos inicialmente;

V. Um curso nesses moldes contribui para um melhor desempenho nas atividades do docente online; e

VI. Recomendaria o curso para outros professores que têm interesse em ingressar na carreira de docente online.

No espaço reservado para críticas, sugestões ou comentários sobre a proposta de curso criado, todos os envolvidos parabenizaram a iniciativa da pesquisa e do curso, como destacado nesta fala:

O curso atende às necessidades básicas do tutor em formação porque apresenta uma proposta clara e objetiva, partindo de sugestões que enriquecem o trabalho docente na EaD (Participante 11).

\section{Conclusão}

A elaboração do produto educacional aqui apresentado, o Mapa de Atividades de Design Instrucional de um Curso de Formação para Docentes Online, foi realizada de forma colaborativa com base nos preceitos da pesquisa-ação. As reuniões e os dados coletados nos questionários evidenciam que a proposta atingiu seus objetivos.

Propor um curso de formação continuada para docentes online na modalidade EaD constituiu um grande desafio, uma vez que planejar, selecionar os melhores e mais adequados recursos para as atividades propostas e as avaliações no decorrer do curso, de modo que contemplasse a opinião de todos os envolvidos, não foi uma tarefa simples.

Na elaboração do mapa de um curso virtual para docentes online, a maior preocupação consiste em possibilitar uma formação holística do docente online na instituição de ensino, compreendendo seu papel fundamental e o melhor modo de apresentar a instrução e o conteúdo. O leque de possibilidades pedagógicas apresentado pelos AVA permite a construção de planejamentos diversificados que propiciem a flexibilidade para o estudo.

Com efeito, o mapa de atividades desenvolvido e apresentado neste artigo permite visualizar todos os caminhos que deverão ser passados pelo docente online, de maneira que esse profissional possa mediar, acompanhar e avaliar a aprendizagem de forma autônoma. Os resultados demonstraram que há demandas específicas para a atuação do professor na modalidade a distância, e a criação de cursos de formação continuada para docentes online mostrou-se uma estratégia relevante para facilitar a compreensão do trabalho desempenhado por esse profissional.

A pesquisa aqui apresentada é um ponto de partida que poderá trazer novos frutos, caso seja produzida e ofertada para uma instituição de ensino, com um olhar mais focado na atuação dos docentes online em cada atividade e na interação deles com alunos. Sugere-se a realização de pesquisas mais aprofunda- 
das, fazendo uso do produto aqui proposto ou com algumas adaptações com todo o corpo de docentes online da instituição, analisando os dados de maneira mais robusta e compartilhando com a academia e a sociedade.

\section{Referências Bibliográficas}

BARDIN, L. Análise de conteúdo. São Paulo: Pioneira, 2011.

BARREIRO, R. M. C. Um breve panorama sobre o design instrucional. EaD em foco, v. 6, n. 2, ago. 2016. Disponível em: http://eademfoco.cecierj.edu.br/index.php/Revista/article/view/375/187. Acesso em: 12 jun. 2019. doi:https://doi.org/10.18264/eadf.v6i2.375.

BERNADINHO, H. S. A tutoria na EaD: os papéis, as competências e a relevância do tutor. Revista Paidéi@, Unimes Virtual, v.2, n. 4, jul. 2011. Disponível em: http://periodicos.unimesvirtual.com.br/index.php? journal=paideia\&page=article\&op=view\&path[]=166 Acesso em: 20 nov. 2018.

BRASIL. Portaria $\mathbf{n}^{\circ} \mathbf{2 . 2 5 3}$, de 18 de outubro de 2001. Dispõe sobre a introdução nas instituições de ensino superior do sistema federal de ensino, na organização pedagógica e curricular de seus cursos superiores reconhecidos, a oferta de disciplinas que, em seu todo ou em parte, utilizem método não presencial, com base no Art. 81 da Lei no 9.394, de 1996. Disponível em: http://www2.camara.leg.br/legin/ marg/portar/2001/portaria-2253-18-outubro-2001-412758-norma-me.html. Acesso em: 16 jan. 2019.

BRASIL. Portaria $\mathbf{n}^{\circ} \mathbf{4 . 0 5 9}$, de 10 de dezembro de 2004. Dispõe sobre a oferta de disciplinas integrantes do currículo que utilizem modalidade semipresencial, com base no Art. 81 da Lei $n^{\circ}$ 9.394, de 1.996. Disponível em http://portal.mec.gov.br/sesu/arquivos/pdf/nova/acs portaria4059.pdf. Acesso em: 16 de janeiro 2019.

BRASIL. Decreto $\mathbf{n}^{\circ} \mathbf{5 . 8 0 0}$, de 8 de junho de 2006. Dispõe sobre o Sistema Universidade Aberta do Brasil UAB. Disponível em: http://www.capes.gov.br/images/stories/download/23-11-2017-Decreto-n-5800UAB.pdf. Acesso em: 16 jan. 2019.

BRASIL. Portaria n 1.134, de 10 de outubro de 2016. Dispõe sobre o exercício das funções de regulação, supervisão e avaliação das instituições de educação superior e dos cursos superiores de graduação e de pós-graduação no sistema federal de ensino. Disponível em: https://abmes.org.br/legislacoes/ detalhe/1988/portaria-n-1134. Acesso em: 16 jan. 2019.

BRASIL. Portaria $\mathbf{n}^{\circ} \mathbf{1 . 4 2 8}$, de 28 de dezembro de 2018. Dispõe sobre a oferta, por instituições de educação superior - IES, de disciplinas na modalidade a distância em cursos de graduação presencial. Disponível em: http://abmes.org.br/legislacoes/detalhe/2669/portaria-mec-n-1.428-2018 Acesso em: 16 jan. 2019.

CARR, W.; KEMMIS, S. Becoming critical: becoming critical knowing through action research. Londres: Falmer Press, 1986.

CHAQUIME, L. P.; FIGUEIREDO, A. P. S. O papel do designer instrucional na elaboração de cursos de educação a distância: exercitando conhecimentos e relatando a experiência. ESUD 2013 - CONGRESSO BRASILEIRO DE ENSINO SUPERIOR A DISTÂNCIA. Belém/PA, 10, 2012; São Luiz, Maranhão. Anais eletrônicos. Disponível em: http://www.aedi.ufpa.br/esud/trabalhos/poster/AT2/114065.pdf. Acesso em: 7 set. 2018.

ESQUINCALHA, A. C, et al Sistemas de tutoria em cursos de pós-graduação a distância: o caso do laboratório de novas tecnologias de ensino da Universidade Federal Fluminense. Niterói, 2009. Disponível em: http://reposital.cuaed.unam.mx:8080/jspui/bitstream/123456789/2904/1/da\%20Concei\%C3\%A7\%C3\%A30,\%20Agnaldo.pdf. Acesso em: 15 nov. 2018. 
FILATRO, Andrea. Design instrucional na prática. São Paulo: Pearson Education do Brasil, 2008.

FREIRE, P. Pedagogia do oprimido. 34ª ed. São Paulo: Paz e Terra, 2002.

GATTI, B. A. Formação de professores: condições e problemas atuais. Revista Brasileira de Formação de Professores, v. 1, n. 1, p. 90-102, maio 2009.

LÉVY, P. Cibercultura. 2a ed. Rio de Janeiro: Editora 34, 2000.

MACHADO, L. D.; MACHADO, E. de C.. O papel da tutoria em ambientes EaD. $11^{\circ}$ CONGRESSO INTERNACIONAL DE EDUCAÇÃO A DISTÂNCIA. Salvador, 2004. Disponível em: http://www.abed.org.br/congresso2004/por/htm/022-TC-A2.htm. Acesso em: 15 nov. 2018.

MORAN, J. M. Novas tecnologias e mediação pedagógica. Campinas: Papirus, 2013.

NOBRE, C.; MELO, K. Convergência das competências essenciais do mediador pedagógico da EaD. VIII CONGRESSO BRASILEIRO DE ENSINO SUPERIOR A DISTÂNCIA. Ouro Preto, 2011. Disponível em: http:// pigead.lanteuff.org/course/view.php?id=124. Acesso em: 18 nov. 2017.

PEDROSA, S. M. P. de A.. A educação a distância na formação continuada do professor. Educ. Rev., Curitiba, n. 21, p. 1-15, jun. 2003. Disponível em: http://www.scielo.br/scielo.php?script=sci arttext\&pi$\mathrm{d}=$ =S0104-40602003000100006\&lng=pt\&nrm=iso. Acesso em: 5 nov. 2018.

SANTOS, E.O. dos; TRACTENBERG, L.; PEREIRA, M.. Competências para docência online: implicações para formação inicial e continuada de professores tutores do FGV online. CONGRESSO INTERNACIONAL DE EDUCAÇÃO A DISTÂNCIA, Abed, Florianópolis, dez. 2005.

SANTOS, R. A formação de formadores na cibercultura e a atuação docente universitária. Educação em Foco, Juiz de Fora, v. 23, n. 1, p. 153-174, jan./abr. 2018.

SARTORI, A. S. Educação a distância: novas práticas pedagógicas e as tecnologias da informação e da comunicação. Linhas, v. 3, n. 2, 2007.

SILVA, I. M. M. Múltiplos papéis dos professores na Educação a Distância e práticas de letramento digital. CONGRESSO INTERNACIONAL ABED DE EDUCAÇÃO A DISTÂNCIA, 15, Recife, 2009. Anais eletrônicos. Disponível em: http://www.abed.org.br/congresso2009/CD/trabalhos/252009084314.pdf. Acesso em: 17 ago. 2018.

SILVA, O. S. da. Gestão de equipes de EaD. $13^{\circ}$ CONGRESSO INTERNACIONAL DE EDUCAÇÃO A DISTÂNCIA. Curitiba, setembro, 2007. Disponível em: http://pigead.lanteuff.org/course/view.php?id=121. Acesso em: 30 nov. 2019.

VIGOTSKY, L. S. A formação social da mente: o desenvolvimento dos processos psicológicos superiores. São Paulo: Martins Fontes, 1991.

ZARIFIAN, P. Objetivo competência: por uma nova lógica. São Paulo: Atlas, 2001. 